\title{
Application of Quality Tools to Reduce Failure Identification in an Automotive Production Line
}

\author{
Cleginaldo Pereira de Carvalho, André Modesto Gonçalves
}

\begin{abstract}
Department of Industrial Engineering, University of the State of São Paulo, Faculty of Engineering of Guaratinguetá, São Paulo, Brazil. Avenida Dr. Ariberto Pereira da Cunha, 333, Pedregulho, Zip Code: 12516-410.

*Corresponding author
\end{abstract}

Received: 30 Jan 2021; Received in revised form: 29 Mar 2021; Accepted: 30 Apr 2021; Available online: 21 May 2021

\begin{abstract}
Quality tools utilization is a reality in several industry segments, including automotive. Its adoption comes from the business needs of more robust and reliable process, promoting actions that reduce deviations and losses related to rework, through teamwork activities and easy visualization graphic tools that reach all operation levels. This case study found the effectiveness of quality tools application on an engine factory with the target to solve issues related to identification issue and increase process traceability through a Kaizen activity, where during a discussion were utilized some quality tools such as Pareto Analysis, Ishikawa diagram, 5 Whys, $5 \mathrm{WIH}$ and brainstorming. As results, it was possible to reach more than 50\% evolution on the engines identification inconsistencies indicator. At the end of the study, it was found too additional benefits that came from a cross-functional team with several departments from the studied factory, such as paper waste reduction and simple automation tool application within logistic process, items that align the production process to the market demand of paperless concept application and increase the process automation level.
\end{abstract}

Keywords - Automotive, Automation, Kaizen, Quality tools.

\section{INTRODUCTION}

This study was idealized based on the possibility of performing an evaluation of the practical application of the quality tools that are so demanded in the current market to solve a quality problem found in a manufacturing environment.

Industry in general is undergoing a transformation related to the implementation of the Industry 4.0 concept (or at least modernization of Industry 3.0) in which automation levels are much higher compared to current facilities and processes become more robust and consequently have greater reliability and data transparency according to [1].

[2] concluded in a study with auto parts companies in Thailand that total quality management is mainly affected by strategic planning, product quality, knowledge management and the application of new technologies and innovations in their processes, and also states that this last point (Technology and Innovation) will be determinant in defining the level of competitiveness of these companies in the market.

For [3] automotive companies will continue in this search for innovations in processes related to automation to reduce costs and increase productivity, but the transformation to fully automated industries will still elapse for a considerable time, due to the very high investment to change the design of production processes, because only automating the current processes will not be enough, being necessary totally innovative techniques in manufacturing to meet the new designs and processes of the future.

[4] highlights the impact of the constant evolutions of the markets on the application of continuous improvement tools by companies in all industries. And from this high level of competitiveness and market volatility, cost reduction activities are highly demanded, but always with improvements in product and/or service quality being worked in parallel. 
To reduce the levels of rework, to have better processes and to implement a culture of continuous improvement, it is important that quality tools are used and that the engagement of people and employees involved in the process in the culture of continuous improvement is also worked on to improve the organizational climate, which allows us to state that large investments are not always necessary to improve the quality of the final product [5].

With the intention of validating the scientific relevance of the proposed study, searches were conducted in the [6] and [7] databases with the key words of the work. Thus, it was possible to identify the relationship between the automotive industry and Quality tools from the number of publications and citations on the themes when searched together: 1438 publications in the period from 1995 to 2021.

At the same time, it was possible to notice that combined the themes traceability and automation, the number of publications was reduced or null in the researched databases. Among the publications found, the great majority is related to traceability in product development, and not to the production process itself or to the products.

When centralizing the search for the main identified combination of key words (Automotive; Quality tools) in the period from 2015 to 2021, we have a trend of growth of publications related to the theme in the [7], except for the year 2020 whose volume of publications presented a small reduction in comparison with the volume of 2019.

Thus, this research is justified because, at the same time that it promotes a benefit through the use of quality techniques and tools in the company in question, it contributes to the scientific community by relating themes that so far are not in publications in the researched databases.

The objective of this work is to promote improvements in the process of moving engines by applying quality tools to contribute to the solution of engine identification problems in an automotive industry based in the Sul Fluminense region of the state of Rio de Janeiro - Brazil.

The work was divided into 4 chapters: Chapter 1 consists of an introduction of the theme and the justification for conducting the study. Chapter 2 presents the theoretical framework of the research. Chapter 3 details the development of the study and describes the research method. Chapter 4 presents the results and the entire development of the work with details of the quality tools used, and in Chapter 5, there is a conclusion regarding the entire research work to validate the objectives proposed in the study.

\section{THEORETICAL BACKGROUND}

\section{$2.1 \quad$ Automotive Industry}

For [8] companies in the automotive sector in general, have improvement programs that seek a greater involvement among all employees, from the operators to the managerial level, which provides a broad environment of continuous improvement and problem solving, and from this environment, the small improvements in the process can be freely suggested by the operators who can follow the implementation with support from technicians, engineers and process managers, while the most impactful improvements occur in a timely manner.

[9] concluded that automation is a great option to improve and enhance the quality and production of an automotive company by allowing an increase in agility, flexibility, and traceability in the processes. The application of robots is widely used for these purposes, but for some of these uses may become unfeasible due to the high cost involved and the space required for installations.

According to [8], in the automotive sector, quality improvement actions within companies are characterized by a participatory culture, involving shop floor strategies and also those coming from management levels, which allows the participation of a high number of employees, having the supervision and collaboration of managers and with the program being managed by a department intended for continuous improvement.

\subsection{Quality in Organizations}

Processes are an ordered sequence of operations that transform inputs into outputs for internal or external customers. In these operations and sequences are the opportunities for improvement that companies should focus their efforts on to add more value to the final product and increase their competitiveness. And one of the main factors that determine the level of consumer demand to have their needs met is quality [10].

According to [11], the principles ordered for quality management that demand high commitment and great effort from all members of a company, especially the highest hierarchical levels, are: total customer satisfaction, participatory management, human resources development, constancy of purpose, continuous improvement, management and process control, information dissemination, delegation of activities, technical assistance, management of interfaces with external agents and quality assurance.

With the advancement of technology and the increase of competitiveness in the markets, it is possible to observe the growing demand for quality improvement and reduction of process failures, and for this reason companies from 
virtually all segments have been seeking innovations to have increasingly reliable production processes, and that present a quick response to variations in demand and less risk of quality problems in the final product [12].

In this context of competitiveness, companies need to reduce the levels of rework in their production processes so that this additional cost related to the waste of inputs and labor intended for these rework operations does not significantly impact the profitability of their products and, ultimately, the competitiveness of these companies in their market segment [13].

At the same time that there is a demand for a higher quality product, the level of competitiveness among companies also demands that products meet all customer needs so that market shares are larger, consumer loyalty guaranteed, and profitability increased [14].

\subsection{Quality Tools}

[11], characterizes the Quality tools as important instruments to bring into practice all the theory of quality. The application of these tools makes the problems of different orders to be identified, elucidated, and solved in a direct and simple way, even those more complex problems found in business environments of all segments and sizes.

The use of quality tools can be considered very important in both the academic and industrial environments due to the low cost of implementation and the practicality and ease of application. And the application of these tools helps companies to make decisions based on facts and data in a simpler way than complex statistical analysis [15].

[16] classifies the main benefits of applying quality tools with increasing quality levels, reducing waste, minimizing rework time, and standardizing processes and products, which consequently results in reduced production costs and benefits to society as a whole.

The main objectives of quality tools are, for [11], to simplify the visualization and understanding of problems, to summarize knowledge and conclusions, to promote the stakeholders' creativity, to facilitate the knowledge of the process, to provide elements for its monitoring, and to enable process improvements. And in summary, quality tools can be divided into 3 groups: support tools, basic tools and advanced tools.

\section{$2.4 \quad$ Process Mapping}

The graphical representation of all steps that arrange a process allows the global view of the activity and also the detailed characteristics of these steps and how they are interconnected, which makes the critical operations are highlighted and the focus of improvements is clearly represented [13].

This article can be downloaded from here: www.ijaems.com
For [17], process mapping consists of demonstrating the logical sequence and interaction of activities. Despite the huge variety of ways of development, all methods aim to identify the standardized procedures that are performed in the process as a source of information for decision making.

[15] describe a flowchart as simply a diagram-like representation of the process flow, with each step divided into different types of figures connected by arrows. Each figure represents a type of operation, between logistics, storage, transportation, and operation. The use of this standardized and practical tool facilitates the understanding of all those involved in a process.

According to [18], some of the benefits identified in the application of process mapping are the standardization and control of processes, improvement of quality levels, identification of operation bottlenecks and consequently elevation of production outputs. From the critical analysis of the process mapping, it is possible to identify which activities do not add value to the product and have a better operation of the production, and these evolutions allow the product and/or service to have a better level of acceptance by the final consumer.

\subsection{Pareto Analysis}

[19] describe the Pareto diagram as a graphical representation performed through vertical columns, with one axis representing the failure modes and another with the numbers of occurrence of decreasingly. It is usually used to represent the frequency of occurring causes, which allows the prioritization of the main failure modes for decision making.

For [20], the basis of the Pareto Analysis is the principle that $80 \%$ of occurrences are caused by $20 \%$ of all causes, which allows observing in a simple and practical way, which are the main offenders of a particular indicator, and after performing this survey, proceed with the construction of a table containing the absolute frequencies of each cause analyzed.

According to [15] the Pareto diagram is a tool widely used to define the priorities of various types of problems, serves to schematize and facilitate the visualization of problems encountered, and has as its main function to analyze and understand the criticality of the problems, and thus separate the many trivial problems of the few vital to the fluidity of the process.

\subsection{Cause and Effect Diagram (Ishikawa Diagram)}

According to [11], the cause and effect diagram (also known as fishbone diagram) has the purpose of organizing information by similarity according to 6 main axes, usually called six M (method, material, machines, environment, labor, and measurement), which allows the identification 
and visualization of the causes of a problem or effect in a clear and targeted manner.

[21] conducted a study of applying the seven basic Quality tools to reduce defects in an automotive industry and was able to conclude that after the use of the Cause and Effect diagram, defects reduced dramatically, and although all tools have their usefulness and share in solving problems, the cause and effect diagram was the most impactful for allowing the identification of the root cause of the problem and what its potential effects are.

According to [22], the application of the Ishikawa method for identifying the root cause of a problem in conjunction with other tools of the lean production concept allowed the identification and reduction of waste in the inspection and packaging processes in an auto parts company.

For [23], the Ishikawa diagram is an interesting and practical tool to be used in brainstorming and problem analysis with diversified teams due to its simplicity of use.

\subsection{Brainstorming}

For [24], the brainstorming (also known as "brainstorming") has as main objective to facilitate that the ideas are created starting from the main concept of deferred judgment, avoiding that the mental barriers hinder the activity and the imagination, which makes the creativity to be used freely, without there is a prior judgment that an idea is bad, leaving the evaluation of the solutions proposals generated to be held in a second stage of the activity.

[11] classifies the tool as very flexible, due to the possibility of application in different contexts and for different purposes, such as: product development, systems implementation, detailing activities, solution proposition for specific problems, among others. And to ensure the effectiveness of the tool, it is suggested that the team involved should be previously trained in the tool, in order to enhance the quality of idea generation.

[25] describes that the main benefits of using brainstorming are the fact that it stimulates open thinking, which enthuses the group and avoids the domination of the team involved by a few members, and thus allows everyone's creativity to be shared, while the final solution is formulated by the group.

\section{$2.8 \quad 5 \mathrm{~W} 1 \mathrm{H}$}

For [26] this tool aims to bring together the information needed to act to solve a problem and synthesize the work action plan so that it is clear to everyone how the process improvement will be carried out. Briefly, it consists in organizing a list of actions that allows having all the problems quantified in a single table.
The acronym $5 \mathrm{~W} 1 \mathrm{H}$ has its formation based on key questions so that essential information is provided in a clear way for an activity to be conducted and avoid misunderstandings between those involved in the work group, so [11] signals that normally all elements of the activities are specified as much as possible in this final stage of planning the activity. The key questions that refer to the acronym $5 \mathrm{~W} 1 \mathrm{H}$ are listed as follows:

- What (What): What will be done? What tasks are considered to attack the root cause?

- Who: Who is responsible for the task? Which department is involved?

- When: When should it be done? What is the deadline for this step?

- Where: Where will this activity be executed?

- Why: Why was this task considered?

- How: How will the task be accomplished? What is the method?

Some authors, such as [25], also consider adding one more $\mathrm{H}$ to the tool, which stands for How much (how much does it cost to perform this activity?).

\section{$2.9 \quad$ Kaizen}

Kaizen is a word of Japanese origin formed by two other words: Kai (change) and Zen (better), which in a literal translation allows us to say that the word means to change for the better.

[27] describes the Kaizen philosophy as a simple essence directly related to continuous improvement that involves everyone, from operators to company managers. And it signals that this philosophy is not only related to work, but that the experience and way of life, whether at work, in society, or at home, deserves to be continuously improved.

Currently the Kaizen methodology has been widely used in business due to its low cost of implementation and by acting directly on how to minimize waste required, reduce process variability and promote continuous improvement in various departments and thus increase the efficiency of operations in general [19].

[4] reports the effectiveness of applying Kaizen combined with other Lean Manufacturing tools to reduce costs and also to improve quality in a textile industry by allowing the solution of problems that could devalue the company's brand and consequently impact its operational results.

The implementation of Kaizen promotes results in a short period of time and with a low level of investment, considering that the pillars of the tool are the collaboration among the members involved and the continuity of this 
cooperation, considering that the employees will make improvements in order to reach the goals established for a certain process [27].

\subsection{Paperless}

According to [28], the concept of paperless manufacturing applied in an automotive component welding industry can present benefits both in record completion time, paper cost reduction, and additional benefits and improvements to the company's productivity such as in document controls, communication, work environment, daily activities, and customer service.

For [1] companies currently implement automations and digital information controls systems to reduce paper documentation and facilitate the management of their process information throughout the product life cycle. This has been a major activity in the economy, and companies have the option to either upgrade current systems through gradual and slower automation, or else replace all of the software used and its elements, which allows for faster change in this transition of technologies and concepts.

[29] depicts some of the goal opportunities to be drawn from a company adopting the paperless strategy and thus enabling increased efficiency of its operations, as well as reduced operation cycle time, improved traceability of records, ease of data collection for periodic process reporting, promotion of a sustainable process, and an overall improvement of the process as a whole.

\section{MATERIAL AND METHODS}

The present research can be considered of an applied nature, as it aims to generate knowledge to apply to a particular problem. It has a qualitative approach, that is, its argumentation is based on the results through analysis and perceptions, and from the point of view of objectives it has a descriptive character and was applied through a case study in an automobile industry located in the Sul Fluminense region of the state of Rio de Janeiro - Brazil based on the comparison of data and indicators for the years 2018 and 2019.

[30] describes the case study as an empirical investigation, considering the deep and detailed investigation of an event that occurred in the present time in a real environment, with the aim of assuming an understanding that manages to gather relevant contextual conditions for the topic addressed, which allows stating that the case study method is not only a defined and applied strategy for data collection nor an isolated structured project, but rather encompasses several activities together so that it is possible to answer the research questions.
For [31], the case study has its structure defined in four main phases, the first being the delimitation of the theme of the case to be studied, then data collection, understanding and evaluation of these data collected and finally the preparation of a case study report.

The development of the work begins with a literature review on the delimited theme, and the selection of the problem of identifying motors to conduct the case study. With the problem defined, observations were made at the site of the failures for a better understanding of the situation and the consequent collection of data so that the analyses could be based on facts. In possession of the information about the case, the interpretation of the data and the evaluation of the intensive discussion session that was applied with the group for the use of the quality tools and the proposition of solutions that would meet the objectives of reducing the identification failures had its effectiveness proven from the data obtained.

The method chosen to develop this work was the case study, which is described by [32] as an opportunity to expand the awareness of real events in environments experienced by those involved and from this, create new ways of acting and theories for solving these problems based on the defined theoretical conceptual framework.

Considering the methods of execution of the research and the entire process of engine identification, a multidisciplinary group was created to propose solutions related to the failures of engine identification in the production process. The work began with interviews conducted with each of the stakeholders in the process to prepare for a day of discussion with the team.

During the intensive discussion activity, the team used the Process Mapping tool to identify the process gaps, and also performed a more detailed root cause analysis with the team together through some quality tools. The second step of the activity was the organization of the process improvement opportunities through brainstorming and the creation of an action plan through the $5 \mathrm{~W} 1 \mathrm{H}$ tool with the possible solutions for the identified gaps.

With the action plan developed, the process improvements were implemented in the following weeks and once all action items were completed, the results and additional benefits achieved by the group were verified.

\section{RESULTS AND DISCUSSION}

In the automotive industry, the traceability of vehicles and engines is done through serial numbers recorded in the chassis (vehicles) and cylinder block (engines) that have their data registered and computed in a production control system at each step of the process completed. 
The identification of the engines is done through a paper label that contains several information such as the engine identification number, the engine model, destination, identification code, date and time scheduled for manufacturing, barcodes, and QR Codes containing the necessary information for systemic registration of the engine's status in the production process.

Initially the label's layout was conceived by the company's headquarters and its format contemplates 3 parts detachable from each other: one that is retained by the logistics team for shipment registration in the production control system and the other two parts that accompany the engine to the vehicle plant, where they are discarded after being used for registration in the system.

Each label follows its respective engine from the beginning of the production process when recording the engine's serial number until it is connected to the transmission in the vehicle plant, as shown in the process map in Fig. 1. This type of label is not fixed to the engine and there is the risk of losing or exchanging it with those of other units during the engine's movement flow.

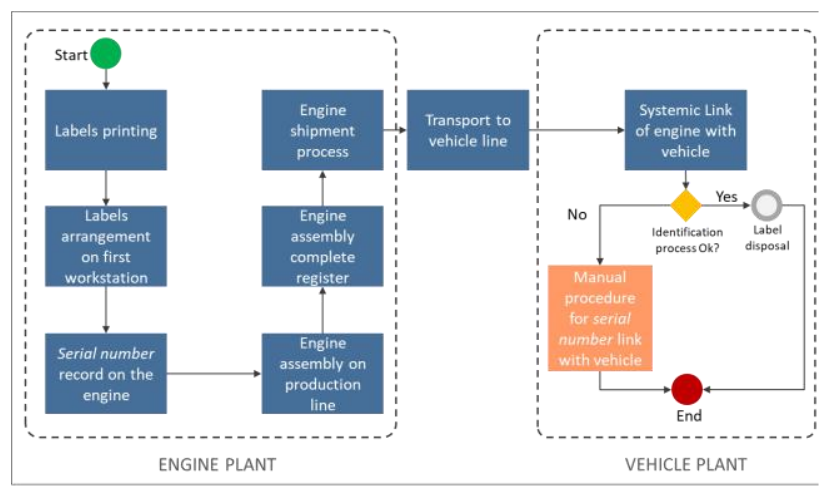

Fig. 1: Process Flow for the handling for the engines tags

In Fig. 1, it is possible to see that whenever the identification process through the bar code reading of the engines presents some failure, it is necessary to perform a manual procedure to finalize the systemic link of the engine with the vehicle.

The problem in the identification of engines during the production process and movement of the engine units was characterized. From this, there were impacts in quality indicators of the process and a new manual activity was demanded to solve this identification failure. At each failure occurred, a person from the Manufacturing team becomes responsible for making a call (via radio or cell phone) to the Production Control sector and to inform the engine codes and the respective vehicle for the manual linking in the operational system and also the reason for the failure to file the information.
In order to evaluate the reasons for the identification failures that occurred at the customer, a Pareto analysis was performed (Fig. 2) to identify the main causes of the problem by number of occurrences over a one-year period.

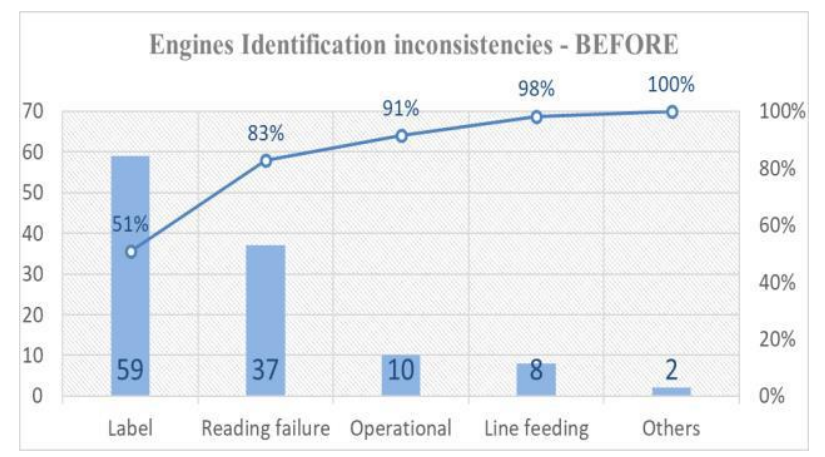

Fig. 2: Number of the identification fails in the inner client-BEFORE

In this analysis, it was possible to identify based on the data in Fig. 2, that $51 \%$ of failures are related to the labels, which illustrates the need for immediate action on the motor labels, the main reason for identification failures in the internal customer. The second main reason $(32 \%)$ were reading failures that are related to the QR Code reader device not working properly, and the third main reason $(8 \%)$ are operational failures in the QR Code reading process. Some secondary problems that were not part of the scope of the project were also identified.

In order to classify the identified failures and map the main causes of the problem for the proposition of efficient solutions a Cause and Effect Diagram was prepared by the team, where the causes were divided according to the 6M's (Method, Machine, Labor, Environment, Material, and Measures) and the graphic representation is in Fig. 3.

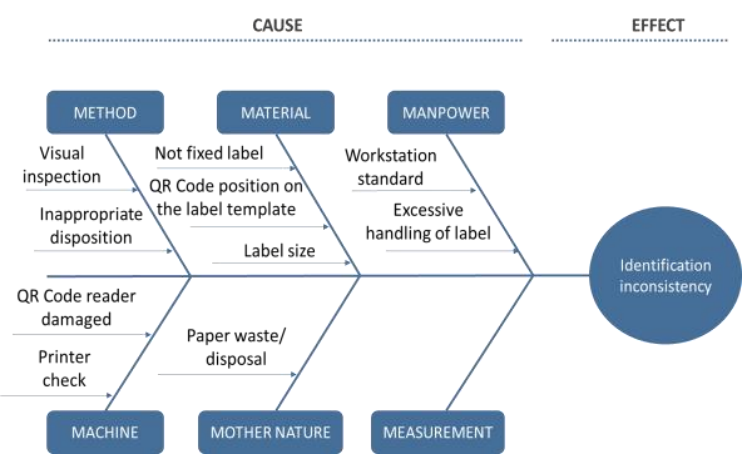

Fig. 3: Ishikawa Diagram 
Considering the current situation already known by everyone on the team and the main causes of the problems identified, we began the stage of defining the solutions that will be implemented.

From this deeper analysis of the main causes, the 5 whys tool was used for each of the main failure modes related to the motor labels with the objective of arriving at a root cause for each failure mode, and then propose, through the use of brainstorming, solutions for the reduction of motor identification failures.

Once the main solutions needed to address the motor identification problem were defined, the group started the last stage of the intensive discussion, which was the creation of a detailed action plan using the $5 \mathrm{~W} 1 \mathrm{H}$ tool, where it was possible to create a document that could clarify to everyone involved what the expected timeframe was, the reasons for each solution, and how they should be broadly accomplished.

This $5 \mathrm{~W} 1 \mathrm{H}$ tool proves to be of great value in avoiding conflicts due to the lack of alignment of the expectation for each activity in terms of deadline, responsibility, and justification, because at this point all those responsible build together and are part of the plan defined for the solution of the problem.

Once the solution priorities were defined, the team implemented the solutions using as a basis the action plan built using the $5 \mathrm{~W} 1 \mathrm{H}$ tool. During the implementation some adaptations in the action items were necessary, and from these actions it was possible to identify a series of improvements in the identification process as a whole.

A new label model was defined by the group with dimensions six times smaller than the one previously used and a different type of paper than the previous one, thus the value of the new label became $60 \%$ smaller, the printing time was reduced by more than $50 \%$, in addition, paper disposal was reduced by almost ten times in comparison with the previous label, since the label now sticks to the engine.

In addition to the benefits created by the new label, improvements were also identified in the engine logistic sequencing process, where with the previous model it was necessary to file a paper stub detached from the label to ensure the physical record of the information for sending the engine to the vehicle line.

To enable the use of this adhesive label (without the stub previously used by the logistics team), a database was created in an electronic spreadsheet that is fed from a simple computer automation that translates the information collected by the logistics operator through a QR Code reading device of the engine label into the necessary data to register the systemic note in the engine shipment process.

In the production process of the vehicle plant there were also additional benefits related to the reduction of the paper disposal operation and the change of the engine reading location, which facilitated the operation and reduced the chances of engine reading error with another part that has a similar process in the same workstation.

Because it was a multidisciplinary project, and involved many departments (13 of the company in question), it demanded a high number of alignment meetings and additional tasks so that the solutions could be applied successfully, since many people saw the proposed solution with resistance because it demanded a significant change for some departments of the company, and one of the points that must be worked on for improvements in the company in question is the culture of resistance to change.

Finally, the result of inconsistencies in the identification of engines in the period of one year after the implementation of the improvements defined by the group was evaluated, as shown in Fig. 4.

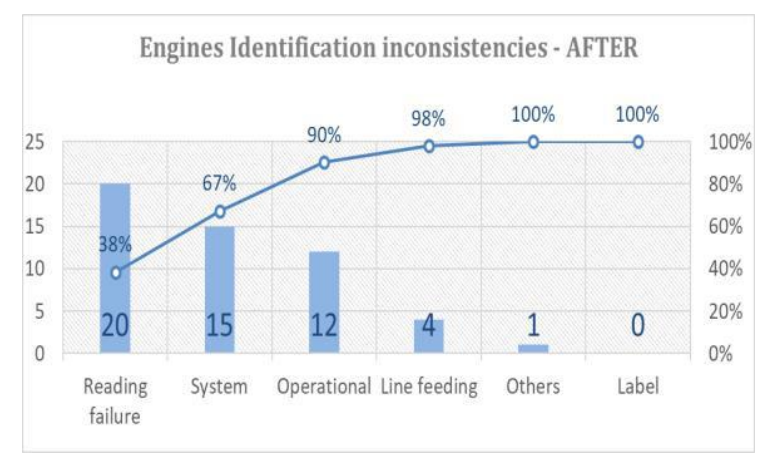

Fig. 4: Number of the identification fails in the inner client-AFTER

The total number of failures that occurred after the implementation of the proposed improvements was reduced by more than $50 \%$ (from 116 occurrences to 52) and the number of inconsistencies due to the label was zero (from 59 to none).

\section{CONCLUSION}

The objective of the research was to promote the application of quality tools in the solution of motor identification problems and, through the use of: Process Mapping, Pareto Analysis, Ishikawa Diagram, 5 Whys, Brainstorming and $5 \mathrm{~W} 1 \mathrm{H}$, it was possible to evidence that the process had a significant reduction in the level of failures in the studied process and to verify that the quality tools were efficient in solving this type of identification problems. 
One of the objectives of the case study was to highlight the possibilities of additional benefits from projects involving cross-functional teams, and from the application of the aforementioned tools it was possible to confirm that the activity performed with the involvement of a crossfunctional group provided a solution that met not only the defined problem, but also involved additional benefits for the company such as the reduction of paper discarded daily, contributing to the implementation of the paperless concept in a production process of the industry in question, cost reduction, and also for the use of automation tools in the sequencing and shipping logistics process of the engines.

The contribution of this work to the academic environment and to the automotive sector could be evidenced by allowing the dissemination of concepts related to quality tools and the automotive industry. Based on the theoretical framework used and the literature researched, it was possible to confirm, from the strong relationship identified between the themes, the important role of quality tools in solving problems in the automotive industry.

The present work contributes to the evaluation of the literature in question through a qualitative analysis of the application of quality tools in the automotive industry and had as a limitation the non-use of complex statistical tools for a deeper quantitative analysis of the root causes and also for the prioritization of the available solutions.

As with all research with a qualitative approach, this study presents certain restrictions as to the generalization of the results obtained, and the evaluation of the same type of problem in other companies in the industry is a suggestion for further study.

It is also recommended as opportunities for future work the use of analysis of variance to understand quantitatively also the possible further improvements in the process of engine identification. Another opportunity identified was the intensification of the frequency of failure assessment by the teams through the creation of a KPI to control this type of problem, which would allow for a periodic indepth evaluation of each occurrence, its root cause, and consequently propose solutions in a shorter period of time.

\section{ACKNOWLEDGEMENTS}

The authors wish to acknowledge the University of the State of São Paulo, Faculty of Engineering of Guaratinguetá, for its assistance during the research period.

This article can be downloaded from here: www.ijaems.com

\section{REFERENCES}

[1] Zakoldaev, D. A., Shukalov, A. V., Zharinov, I. O. \& Zharinov, O. O. (2019). Modernization stages of the Industry 3.0 company and projection route for the Industry 4.0 virtual factory. IOP Conference Series: Materials Science and Engineering, 537, 032005. doi:10.1088/1757899X/537/3/032005

[2] Petcharit, A., Sornsaruht, P., \& Pimdee, P. (2020). An Analysis of Total Quality Management (TQM) within the Thai Auto Parts Sector. International Journal of Online and Biomedical Engineering, 16(2), 131-145. https://doi.org/10.3991/ijoe.v16i02.11917

[3] Harbour, R., \& Schimidt, J. (2018). Tomorrow's Factories Will Need Better Processes, Not Just Better Robots. Harvard Business Review. Retrieved from https://hbr.org/2018/05/tomorrows-factories-will-needbetter-processes-not-just-better-robots.

[4] Carvalho, C. P., Gonçalves, L.W.N., \& Silva, M. B. (2017). Kaizen and 5S as Lean Manufacturing Tools for Discreet Production Systems: A Study of the Feasibility in a Textile Company. International Journal of Research Studies in Science, Engineering and Technology, 4(7), 1-12

[5] Carvalho, A. F., \& Ribeiro, B. M. B. (2020). Aplicação do ciclo PDCA e ferramentas da qualidade para redução do índice de retrabalho em uma linha de laminação de uma empresa do setor automotivo. Retrieved from http://www.abepro.org.br/biblioteca/TN_STO_345_1773_4 0754.pdf

[6] Scopus. (2021). Base de dados. Retrieved from www.scopus.com

[7] Web of science. (2021). Base de dados. Retrieved from www.webofknowledge.com

[8] Gonzalez, R. V. D., \& Martins, M. F. (2016). Capability for continuous improvement - Analysis of companies from automotive and capital goods industries. The TQM Journal, 28(2), 250-274.

[9] Costa, R. J. S., Silva, F. J. G., \& Campilho, R. D. S. G. (2017). A novel concept of agile assembly machine for sets applied in the automotive industry. The International Journal of Advanced Manufacturing Technology, 91, 4043-4054. https://doi.org/10.1007/s00170-017-0109-4

[10] Santos, A. S. R., Scaquetti, R. A. B., Azevedo, S. A., \& Bernini, D. S. D. (2020). A aplicação das ferramentas da qualidade para a melhoria de um processo industrial. Retrieved from http://www.abepro.org.br/biblioteca/TN_S TP_345_1772_39940.pdf

[11] Oliveira, O. J. (2015). Curso básico de Gestão da Qualidade (5. ed.). CENCAGE Learning.

[12] Conceição, S. V., Rodrigues, I. A., Azevedo, A. A., Almeida, J. F., Ferreira, F., \& Morais, A. (2009). Desenvolvimento e implementação de uma metodologia para troca rápida de ferramentas em ambientes de manufatura contratada. Revista Gestão e Produção, São Carlos, 16(3), 357-369.

[13] Paladini, E. P. (2012). Gestão da qualidade: teoria e casos (2. ed.). Rio de Janeiro: Elsevier Editora Ltda.

[14] Carpinetti, L. R. (2010). Gestão da qualidade: Conceitos e técnicas (1. ed.). São Paulo: Atlas. 
[15] Nagarajan, V., Ganesh, V. V., Vishal, V., Vimal, S. R., \& Pragadish, K. (2017). Application of Quality Tools in a Plastic Based Production Industry to achieve the Continuous Improvement Cycle. Quality - Access to Success, 18(157), 61.

[16] Gozzi, M. P. (2015). Gestão da qualidade em bens e serviços (1. ed.). São Paulo: Pearson Education do Brasil.

[17] Slack, N., Brandon-Jones, A., \& Johnston, R. (2018). Administração da produção (4. ed.). Rio de Janeiro: Atlas.

[18] Oliveira, E. F., \& Nascimento, D. C. O. (2019). Mapeamento de Processos em uma Empresa do Ramo Metalomecânico: Um Estudo de Caso. Vértices, Campos dos Goytacazes/RJ, 21(3), 514-529.

[19] Carvalho, C. P., \& Pereira, W. L. B. (2015). Kaizen: A Continuous Process of Improving Companies. REGET Revista de Gestão \& Tecnologia, 3(3), 11-19.

[20] Lucinda, M. A. (2010). Qualidade: fundamentos e práticas para cursos de graduação (1. ed.). Rio de Janeiro: Brasport.

[21] Memon, I. A., Ali, A., Memon, M. A., Rajput, U. A., Abro, S. A. K., \& Memon, A. A. (2019). Controlling the Defects of Paint Shop using Seven Quality Control Tools in an Automotive Factory. Engineering, Technology \& Applied Science Research, 9(6), 5062-5065. https://doi.org/10.48084/etasr.3160

[22] Leite, L. E. (2020). Aplicação do Lean Manufacturing para redução de tempos improdutivos em uma célula de inspeção e embalagem de molas de válvula. Trabalho de Especialização em Gestão da Produção, Faculdade de Engenharia do Campus de Guaratinguetá, Universidade Estadual Paulista, Guaratinguetá, Brasil.

[23] Corrêa, H. L., \& Corrêa, C. A. (2012). Administração de produção e operações: Manufatura e serviços, uma abordagem estratégica (3. ed.). São Paula: Atlas.

[24] Machado, S. S. (2012). Gestão da qualidade. Inhumas: IFG. Santa Maria: Universidade Federal de Santa Maria. Retrieved from http://redeetec.mec.gov.br/images/stories/ pdf/eixo_prd_industr/tec_acucar_alcool/161012_gest_qual.p df

[25] Werkema, M. C. C. (1995). As ferramentas da qualidade no gerenciamento de processos (4. ed.). Belo Horizonte.

[26] Martins, P. G., \& Laugeni, F. P. (2015). Administração da Produção (3. ed.). São Paulo: Saraiva.

[27] Imai, M. (1994). Kaizen, a estratégia para o sucesso competitivo (6. ed.). São Paulo: Editora Imam.

[28] Carlos, B. J., Pereira, C. F. M., Munno, V. M. R., \& Correr, I. (2019). Os benefícios de um ambiente paperless em uma linha de soldagem automotiva: pesquisa-ação. Retrieved from http://www.abepro.org.br/biblioteca/TN_STO_000_1634_3 7850.pdf

[29] Johnson, W. (2012). The Paperless Factory: using technology to improve efficiency in high mix and CTO production. Spectrum Assembly Inc., Carlsbad, California, USA.

[30] Yin, R. K. (2015). Estudo de caso: planejamento e métodos (5. ed.). Porto Alegre: Bookman.
[31] Ventura, M. M. (2007). O Estudo de Caso como Modalidade de Pesquisa. Revista SOCERJ, Pedagogia Médica, 20(5), 383-386.

[32] Miguel, P. A. C. (2012). Metodologia de Pesquisa para Engenharia de Produção e Gestão de Operações (2. ed.). Rio de Janeiro: Elsevier: ABEPRO. 